\title{
Uterine Corpus Adenomyosis
}

National Cancer Institute

\section{Source}

National Cancer Institute. Uterine Corpus Adenomyosis. NCI Thesaurus. Code C6996.

The growth of endometrial tissue inside the muscular wall of the uterine corpus. Clinical

manifestations include pain, dysmenorrhea, and menorrhagia. 